\title{
Bcl-2 Affects Survival but Not Neuronal Differentiation of PC12 Cells
}

\author{
Anna Batistatou, ${ }^{1}$ Diane E. Merry, ${ }^{2}$ Stanley J. Korsmeyer, ${ }^{2}$ and Lloyd A. Greene ${ }^{1}$ \\ 'Department of Pathology and Center for Neurobiology and Behavior, Columbia University, College of Physicians and \\ Surgeons, New York, New York 10032 and ${ }^{2}$ Howard Hughes Medical Institute, Washington University, School of Medicine, \\ St. Louis, Missouri 63110
}

\begin{abstract}
Past studies have shown that serum-free cultures of PC12 cells are a useful model system for studying the mechanisms of neuronal death after neurotrophic factor deprivation. These cultures, as well as NGF-deprived cultures of sympathetic neurons, manifest an endonuclease activity that leads to "apoptotic" internucleosomal DNA cleavage. Overexpression of the proto-oncogene bcl-2 blocks apoptotic death in various cell types. To study the actions of this protein in neuronal cells, we derived PC12 cell lines stably transfected with a cDNA encoding human bcl-2. It is reported here that lines expressing high levels of the exogenous bcl-2 protein are protected from both death and apoptotic DNA fragmentation caused by removal of trophic support. However, expression of high levels of exogenous bcl-2 neither mimics nor interferes with promotion of neurite outgrowth by NGF.

[Key words: bcl-2, DNA fragmentation, NGF, neuronal differentiation, PC12 cells, survival]
\end{abstract}

Neuronal cell death is a prominent feature of vertebrate development. About $20-80 \%$ of neurons in a given developing population ultimately die (Hamburger and Oppenheim, 1982; Oppenheim, 1991). According to the "neurotrophic theory," neurons compete for target-derived trophic factors that maintain their survival, and only those that acquire adequate trophic support avoid death (Purves, 1986; Barde, 1989; Oppenheim, 1989). Moreover, neuronal cell death is not restricted only to development. It also occurs during aging or disease. The mechanism(s) of neuronal death is (are) not yet understood. The ultrastructural changes that occur during naturally occurring neuronal death resemble those of cells undergoing apoptosis (Wright et al., 1983; Server and Mobley, 1991). In addition, in vitro studies with sympathetic neurons deprived of NGF, hippocampal neurons exposed to toxic levels of glutamate, and cerebellar granule cells treated with a neurotoxin reveal that internucleosomal DNA fragmentation, the biochemical hallmark of apoptosis, accompanies these examples of induced neuronal death (Dipasquale et al., 1991; Edwards et al., 1991; Kure et al., 1991).

The rat PC12 pheochromocytoma cell line provides a model system for studying neuronal death (Greene and Tischler, 1976). $\mathrm{PC} 12$ cells survive and multiply in serum-containing medium in the absence of NGF. However, when serum is withdrawn

\footnotetext{
Received Jan. 12, 1993; revised Apr. 20, 1993; accepted Apr. 29, 1993.

We thank Kenneth $\mathrm{K}$. Teng for providing total PC12 cell genomic DNA. This work was supported by grants from the NIH-NINDS.

Correspondence should be addressed to Lloyd A. Greene, Department of Pathology, Columbia University, College of Physicians and Surgeons, 630 West 168 th Street, New York, NY 10032.

Copyright (C) 1993 Society for Neuroscience $0270-6474 / 93 / 134422-07 \$ 05.00 / 0$
}

from PC1 2 cell cultures, about $50 \%$ of the cells die by $24 \mathrm{hr}$ and nearly all die by 1 week (Greene, 1978). Addition of NGF to such serum-free cultures rescues the cells from death. Therefore, in serum-free medium, PC12 cells resemble sympathetic neurons in that their survival can be maintained by NGF. Observations with serum-free cultures of PC12 cells often pertain to NGF-deprived cultured sympathetic neurons. For example, it has been shown that cAMP analogs promote survival of both PC1 2 cells and sympathetic neurons (Rydel and Greene, 1988; Rukenstein et al., 1991). Moreover, the DNA fragmentation characteristic of apoptosis appears early in $\mathrm{PC} 12$ cell cultures after serum withdrawal and in cultures of sympathetic neurons after NGF deprivation (Batistatou and Greene, 1991; Edwards et al., 1991). In addition, aurintricarboxylic acid, a reported cndonuclcasc inhibitor, promotes serum-free survival of $\mathrm{PCl} 2$ cells and NGF-free survival of sympathetic neurons (Batistatou and Greene, 1991).

$\mathrm{Bcl}-2$ is a novel proto-oncogene that appears to affect apoptotic cell death (for review, see Korsmeyer, 1992a,b). It was discovered at the most common chromosomal translocation in human lymphoid malignancies (Bakhshi et al., 1985; Cleary and Sklar, 1985; Tsujimoto et al., 1985), and it has been reported that its deregulated expression prolongs survival of certain hematopoietic cell lines after growth factor deprivation (Vaux et al., 1988; Nuñez et al., 1990). Moreover, in humans, bcl-2 protein appears to be topographically restricted to progenitor cells within mature tissues characterized by apoptotic cell death and to long-lived cells, including certain neurons (Hockenbery et al., 1991). Very recent findings indicate that overexpression of bcl-2 in cultured sympathetic neurons prolongs their survival after withdrawal of NGF (Garcia ct al., 1992). To provide an experimentally useful model for examining the potential action of bcl-2 in the nervous system, we stably expressed human bcl-2 protein in PC12 cells and determined whether it can affect their survival in serum- and NGF-free medium. We also investigated whether bcl-2 expression might either mimic or interfere with the differentiating actions of NGF. Finally, we explored the subcellular localization of human bcl-2 in the transfected cells and examined whether endogenous bcl-2 might mediate the survival-promoting actions of NGF.

\section{Materials and Methods}

Cell culture, transfections, and cell counts. $\mathrm{PC1} 2$ cells were cultured as previously described (Greene and Tischler, 1976, 1982) on collagencoated dishes in RPMI 1640 medium supplemented with $10 \%$ heatinactivated horse serum and 5\% fetal bovine serum (complete medium). Cells were transfected by electroporation with the SFFVBcl-2nl plasmid (SFFVNeo vector containing the entire human bcl-2 open reading frame; Hockenbery et al., 1990) or with the parental vector (SFFVNeo) as 
described previously (Greene et al., 1991). After selection with geneticin (Sigma Chemical Co.), several colonies were isolated and expanded. The resulting clones were cultured in complete medium containing 250 $\mu \mathrm{g} / \mathrm{ml}$ geneticin.

For serum-free experiments cells from various clones were extensively washed in serum-free RPMI 1640 medium, resuspended in the same medium and plated at a density of $8-15 \times 10^{4}$ per well in collagencoated 24-well plastic culture dishes $(0.5 \mathrm{ml}$ of medium/well) in the presence or absence of NGF. Cultures were refed every $2-3 \mathrm{~d}$. At various times the culture medium was removed and replaced with $0.25 \mathrm{ml}$ of a solution that lyses the cell membrane but leaves the nuclei intact (Soto and Sonnenschein, 1985). The nuclei were counted in a hemacytometer. Counts were performed on triplicate wells in every experiment and are reported as mean \pm SEM.

For differentiation experiments, $2-3 \times 10^{5}$ cells per condition were cultured on collagen-coated $35 \mathrm{~mm}$ plastic tissue culture dishes in complete medium containing $100 \mathrm{ng} / \mathrm{ml}$ NGF. Cultures were refed every 2-3 d. After 7 d, cultures were scored for neurite-bearing cells as previously described (Burstein and Greene, 1978). For each clone at least 100 random cells were scored. Counts were performed on duplicate cultures for each experiment.

Western blot (immunoblot) analysis. Cells from various clones were harvested by trituration, washed with ice-cold PBS, and resuspended in a solution containing $150 \mathrm{~mm} \mathrm{NaCl}, 50 \mathrm{~mm}$ Tris, $1 \%$ Triton $X-100$, $5 \mu \mathrm{l} / \mathrm{ml}$ aprotinin, and $50 \mu \mathrm{g} / \mathrm{ml}$ phenylmethylsulfonyl fluoride. After incubation for $10 \mathrm{~min}$ on ice, the samples were centrifuged at 13,000 $\times g$ for $5 \mathrm{~min}$. Protein contents of the supernatants were measured by the Bradford assay (Bio-Rad, Bio-Rad Laboratories); $100 \mu \mathrm{g}$ of protein from each sample was subjected to electrophoresis on an SDS-12\% polyacrylamide gel and subsequently transferred to nitrocellulose filters by electroblotting. The blots were blocked with 3\% milk in PBS for 2 $\mathrm{hr}$ at room temperature and subsequently incubated overnight at $4{ }^{\circ} \mathrm{C}$ with a hamster anti-human bcl-2 monoclonal antibody $(6 \mathrm{C} 8,1: 75$ dilution in PBS with $0.05 \%$ Tween 20; Hockenbery et al., 1990). After incubation with biotinylated goat anti-hamster $\operatorname{IgG~}(1: 250$ in PBS-Tween) for $2 \mathrm{hr}$ at room temperature and with streptavidin-peroxidase for $1 \mathrm{hr}$ at room temperature, the blots were developed with diaminobenzidine and enhanced with nickel chloride $(0.03 \%)$.

Northern blot (RNA) analysis. Cells from various clones were used for isolation of total RNA, by a single-step acid guanidinium thiocyanate-phenol-chloroform extraction method (Chomczynski and Sacchi, 1987); $20 \mu \mathrm{g}$ of RNA per sample was separated on 1\% agarose-formaldehyde gels and transferred to nitrocellulose membranes (Sambrook et al., 1989). Equal loading was confirmed by ethidium bromide staining of RNA in agarose-formaldehyde gels. ${ }^{32} \mathrm{P}$-labeled probe for mouse bcl-2 (Nuñcz et al., 1990) was prepared by the random priming reaction (Sambrook et al., 1989). The blots were hybridized with radiolabeled probe in the presence of $3 \times$ saline-sodium citrate (SSC) at $37^{\circ} \mathrm{C}$ overnight, washed in $2 \times \mathrm{SSC}$ and $0.5 \% \mathrm{SDS}$ at $60^{\circ} \mathrm{C}$ for $2 \mathrm{hr}$, and subjected to autoradiography.

Extraction of DNA and Southern blot analysis for detection of DNA fragmentation. Cells from various clones $\left(4-8 \times 10^{6}\right.$ cells per condition) were extensively washed with RPMI 1640 medium and plated in uncoated $100 \mathrm{~mm}$ plastic culture dishes in RPMI 1640 medium with or without NGF. After incubation for $3 \mathrm{hr}$ at $37^{\circ} \mathrm{C}$, the cells were triturated off the dishes and centrifuged at $800 \times g$ for $5 \mathrm{~min}$, and the pellet was washed with ice-cold PBS. Soluble DNA was extracted as previously described (Hockenbery et al., 1990). Samples were incubated with 50 $\mathrm{mg} / \mathrm{ml} \mathrm{DNase-free} \mathrm{RNase} \mathrm{(Boehringer} \mathrm{Mannheim)} \mathrm{at} 37^{\circ} \mathrm{C}$ for $30 \mathrm{~min}$. All the soluble DNA recovered per condition (total solublc DNA/culture) was subjected to electrophoresis on a $1.2 \%$ agarose gel, blotted onto GeneScreen Plus Membrane (Du Pont/New England Nuclear), and probed with total genomic PC12 cell DNA digested with Sau 3A (Boehringer Mannheim). ${ }^{32} \mathrm{P}$-labeled probe was prepared by the random priming reaction (Sambrook et al., 1989), and hybridization and washings were performed according to the manufacturer's protocol (Du Pont/ New England Nuclear).

Immunolocalization of bcl-2 protein. For confocal microscopy, PC12bcl-2.1 cells were cultured overnight in collagen-coated eightchamber tissue culture slides. Cells were fixed for $20 \mathrm{~min}$ at room temperature with $4 \%$ paraformaldehyde in $\mathrm{PBS}$, and then permeabilized in $0.3 \%$ Triton $\mathrm{X}-100$ in PBS, pH 7.2, with $1 \% \mathrm{BSA}$ and $0.2 \%$ nonfat dry milk (PBS-blocking buffer) for $15 \mathrm{~min}$. After blocking with $1.5 \%$ normal goat serum in PBS for $30 \mathrm{~min}$ at room temperature, cells were incubated with the monoclonal antibody $6 \mathrm{C} 8$ (or with a control hamster monocional antibody) at a 1:50 dilution, for $30 \mathrm{~min}$ at room temperature. They were then incubated with a fluorescein-conjugated goat antihamster IgG (CalTag Laboratories) for $30 \mathrm{~min}$ at room temperature at a 1:100 dilution. Following antibody incubations, cells were washed in PBS and then in PBS-blocking buffer. Streptavidin-Texas red (1:100) was incubated with cells either alone $(1 \mathrm{hr})$ or in combination with both primary and secondary antibodies, at a 1:100 dilution. Cclls were analyzed and photographed using a Bio-Rad Lasersharp MRC500 scanning confocal microscopy system with filters for dual fluorescein and Texas red emissions. A Zeiss Axioplan microscope was used for fluorescent microscopy. Subcellular fractionation experiments were performed as previously described (Hockenbery et al., 1990).

\section{Results}

Expression of human bcl-2 protein in transfected PC12 cells To obtain lines stably expressing human bcl-2, $\mathrm{PC} 12$ cells were transfected with the SFFVBcl-2nl plasmid containing the neomycin resistance gene and the entire human bcl-2 open reading frame driven by the long terminal repeat of the splenic focusforming virus (Hockenbery et al., 1990). Control cells were transfected with the parental SFFVNeo vector lacking the bcl-2 sequence. Twelve independently derived neomycin-resistant clones transfected with the SFFVBcl-2nl plasmid and six neomycin-resistant clones transfected with SFFVNeo were expanded and analyzed. To determine whether the human bcl-2 protein is expressed in these clones, cell lysates were isolated and 100 $\mu \mathrm{g}$ of protein from each was subjected to electrophoresis on an SDS-12\% polyacrylamide gel. The amount of bcl-2 protein in each clone was determined by Western immunoblotting using 6C8, a species-specific anti-human bcl-2 monoclonal antibody. For reference, we used $100 \mu \mathrm{g}$ of cell lysate from RL-7 cells, a human B-cell line that expresses high levels of bcl-2 (Hockenbcry ct al., 1990). We found that the SFFVBcl-2nl-transfected clones express variable levels of human bcl- 2 protein. The results from representative clones are shown in Figure 1. Clones PC12bcl-2.1, PC12bcl-2.2, and PC12bcl-2.3 express the highest levels of human bcl-2 protein, though at somewhat lower levels than in RL-7 cells. Clone PC12bcl- 2.4 expresses relatively low levels of human bcl-2 and in $\mathrm{PC} 12 \mathrm{bcl}-2.5$ this protein is undeteclable. As expected, clones PC12neo.1 and PC12neo.2, transfected with the SFFVneo, do not express human bcl-2.

\section{Expression of bcl-2 mRNA in transfected PC12 cells}

In the above experiments it was not possible to determine the levels of endogenous bcl-2 protein in PC12 cells, since $6 \mathrm{C} 8$ is a species-specific anti-human bcl-2 antibody and since antibodies against rat bcl-2 protein are not currently available. We therefore compared the levels of exogenous and endogenous bcl-2 mRNA in transfected PC 12 cells by Northern blot analysis with a mouse bcl-2 probe. The blots were washed under lowstringency conditions to achieve adequate signals. As shown in Figure 2, three transcripts were detected (indicated by arrows). The most prominent transcript is approximately 4.5 kilobases $(\mathrm{kb})$ and corresponds to the transfected human bcl- 2 cDNA. As expected, it appears only in PC12bcl-2.1, PC12bcl-2.2, and PC12bcl-2.3 but not in PC12neo.2. A less prominent $1.3 \mathrm{~kb}$ band appears in all clones. It does not correspond to any reported mouse transcript, and it could be either nonspecific or another bcl-2 mRNA species recognized by the mouse probe. A third relatively weak band was also detected in all clones and is approximately $7.5 \mathrm{~kb}$. This is probably the endogenous rat homolog of the previously described murine $7.5 \mathrm{~kb}$ bcl-2 mRNA (Negrini et al., 1987; Nuñez et al., 1990). As described below, the levels of this transcript do not correlate with the ability of 


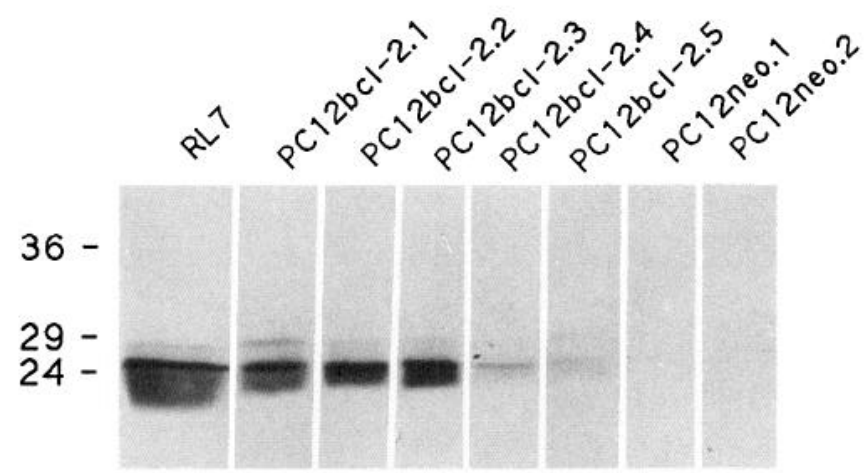

Figure 1. Expression of human bcl-2 protein in transfected $\mathrm{PC} 12$ cells. Cells from clones PC12bcl-2.1, PC12bcl-2.2, PC12bcl-2.3, PC12bcl2.4, and PC12bcl-2.5 (transfected with the SFFVbcl-2nl plasmid) and from clones $\mathrm{PC1}$ 2neo.1 and $\mathrm{PC1}$ neo.2 (transfected with control SFFVneo) were cultured in complete medium and used for isolation of cell lysates; $100 \mu \mathrm{g}$ of total protein per lane was subjected to electrophoresis on an SDS- $12 \%$ polyacrylamide gel and subsequently transferred to a nitrocellulose filter by electroblotting. Western blot analysis was performed as described in Materials and Methods. 6C8, an antihuman bcl-2 monoclonal antibody, was used at a dilution 1:75; $100 \mu \mathrm{g}$ of lysate from human RL-7 cells was used as a positive control. The numbers at the left represent the position of molecular mass markers $\left(M_{r} \times 10^{-3}\right)$.

the cells to survive in serum-free medium and are barely detectable even in the presence of NGF (data not shown).

\section{High expression of bcl-2 correlates with PC12 cell survival in serum-free medium}

Past studies have shown that PC12 cells rapidly die when plated in RPMI 1640 medium without serum, NGF, or other survivalpromoting agents (Greene, 1978; Rukenstein et al., 1991). We determined whether expression of exogenous bcl-2 can affect survival of PC12 cells under such conditions. The SFFVbcl2nl-transfected and SFFVneo-transfected lines were washed extensively and cultured in RPMI 1640 medium without serum or any other additives. At various times cell counts were performed on triplicate cultures. As shown in Figure 3, control clones PC12neo. 1 and PC12neo. 2 behave like the parental PC12 cells (Greene, 1978). Approximately $30-60 \%$ of cells are dead after $1 \mathrm{~d}$ and essentially all cells are dead by 1 week of culture in serum-free medium. Clones PC12bcl-2.4 and PC12bcl-2.5, which are transfected with the SFFVbcl-2nl but express low or undetectable levels of bcl-2, show similar behavior. In contrast, clones PC12bcl-2.1, PC12bcl-2.2, and PC12bcl-2.3, which express relatively high levels of human bcl-2, show consistently enhanced survival in serum-free medium. As shown in Figure 3, approximately $80-100 \%$ of cells are alive after $1 \mathrm{~d}$. Although the number of surviving cells declines after a few days, for clones PC12bcl-2.1 and PC12bcl-2.2 a substantial percentage of cells (about 50\%) are alive after a week or serum deprivation. Clone PC12bcl-2.3 shows a more rapid rate of death but about $15 \%$ of the cells still remain after removal of serum for a week. At longer times the number of surviving cells continues to decline (data not shown).

Figure 4 compares the 1 week serum-free survival obtained with the various lines in serum-free medium supplemented with or without NGF. Regardless of the expression of bcl-2, NGF maintains at least $75 \%$ of the cells for 1 week in serum-free medium. Thus, expression of bcl-2 does not appear to affect the capacity of NGF to promote optimal PC12 cell survival. These

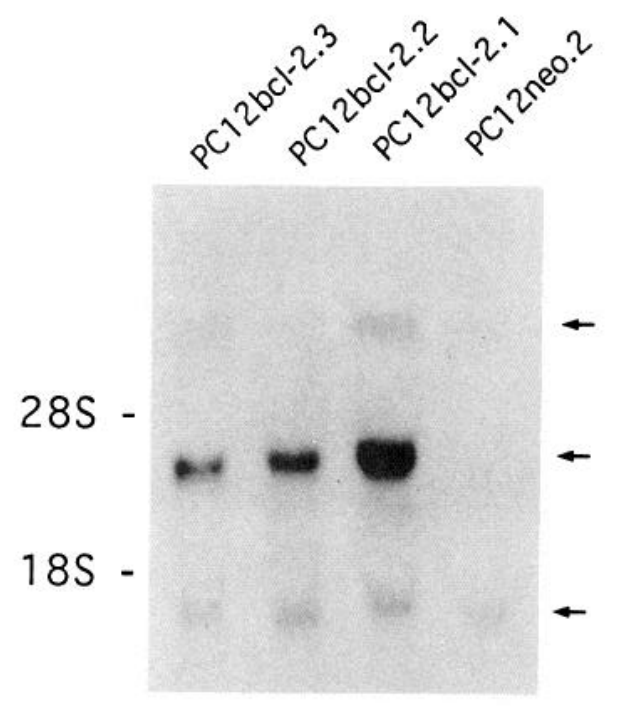

Figure 2. Expression of cross-hybridizing bcl-2 mRNA in transfected PC1 2 cells. Cells from the indicated clones were cultured in complete medium and used for isolation of total RNA; $20 \mu \mathrm{g}$ of total RNA per sample was separated on a $1 \%$ agarose-formaldehyde gel. Northern blot analysis was performed with a mouse bcl-2 probe as described in Materials and Methods. The positions of $18 \mathrm{~S}$ and $28 \mathrm{~S}$ rRNAs are indicated at the left.

data also show that even for those lines expressing the highest bcl-2 levels, the number of cells undergoing long-term survival was less than in the presence of NGF.

\section{Expression of bcl-2 inhibits early PC12 cell DNA fragmentation in serum-free medium}

Previous studies have shown that early internucleosomal DNA fragmentation is specifically associated with $\mathrm{PC} 12$ cell death

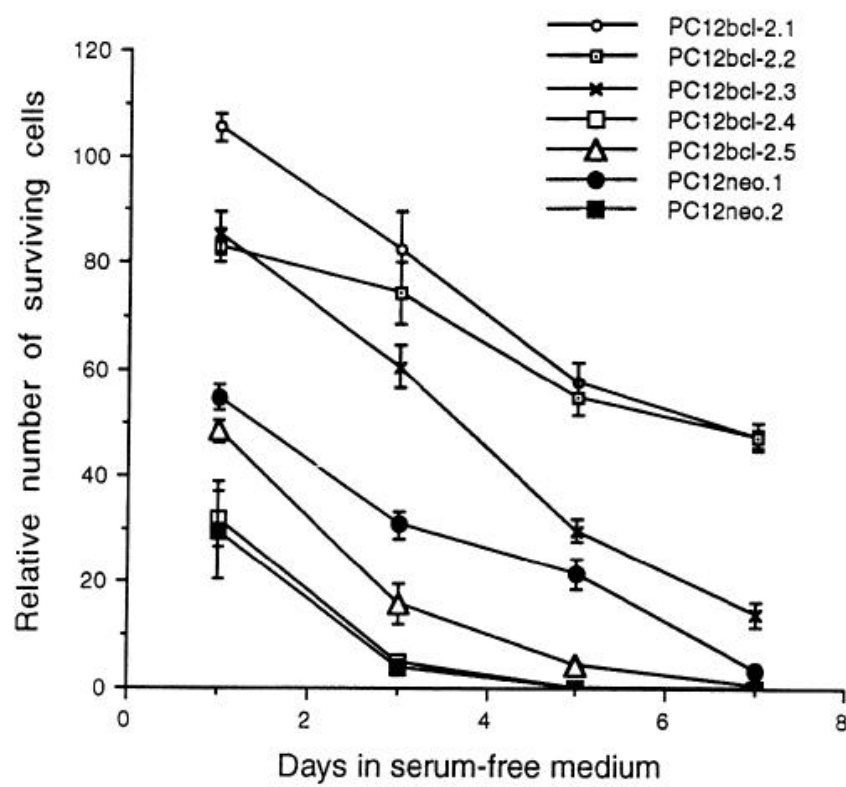

Figure 3. Time course of survival of the transfected clones in serumfree medium. Cells from various clones were washed and plated in serum-free RPMI 1640 medium. Viable cells, in triplicate wells, were counted every $2 \mathrm{~d}$ as described in Materials and Methods. Cell survival data are presented relative to the number of cells in sister cultures treated with NGF for $1 \mathrm{~d}$ (designated as 100). Recovery in the NGF-treated cultures at $1 \mathrm{~d}$ was $116 \pm 2.5 \%$ of the number of cells originally plated. Error bars represent SEM $(n=3)$. 


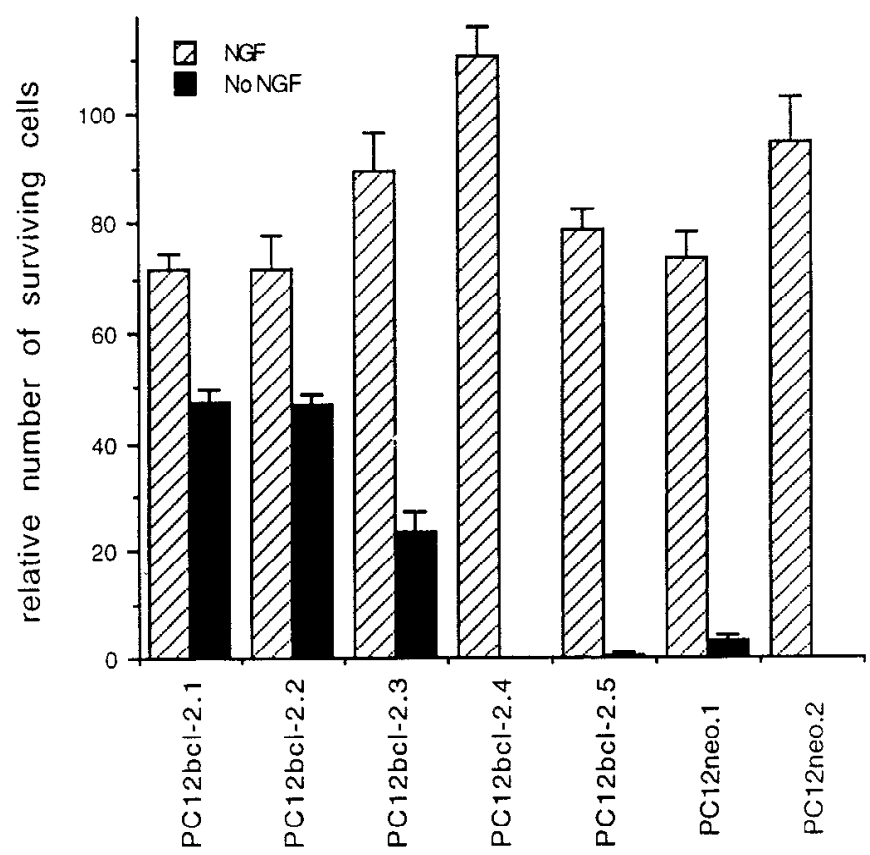

Figure 4. Survival of the transfected clones in serum-free medium in the presence or absence of NGF. Cells from various clones were washed and plated in serum-free RPMI 1640 medium in the presence or absence of $100 \mathrm{ng} / \mathrm{ml} \mathrm{NGF}$. Viable cells, in triplicate wells, were counted after 1 week in culture. Cell survival data are presented relative to the number of cells in sister cultures treated with NGF for $1 \mathrm{~d}$ (designated as 100). Recovery in the NGF-treated cultures (at $1 \mathrm{~d}$ ) was $116 \pm 2.5 \%$ of the number of cells originally plated. Error bars represent SEM $(n=3)$.

after serum and NGF deprivation (Batistatou and Greene, 1991, 1993). This phenomenon is observed as early as $3 \mathrm{hr}$ of culture in serum-free medium and is inhibited if survival-promoting factors such as NGF are present. We examined this parameter in our transfected clones. As shown in Figure 5, clones PC12bcl2.1, PC12bcl-2.2, and PC12bcl-2.3, which express the highest levels of human bcl-2, do not exhibit DNA fragmentation at 3 hr after serum deprivation. In contrast, clones PC12bcl-2.4 and PCl 2 bcl-2.5 behave like the control PC12neo. 1 and PC12neo.2 clones in that they display prominent DNA fragmentation that is inhibited when NGF is added to the serum-free medium. Therefore, it appears that adequate expression of bcl-2 can inhibit the early DNA fragmentation apparent at $3 \mathrm{hr}$ after withdrawal of serum. This is consistent with the ability of bcl-2 to suppress serum-free cell death of the same clones.

\section{Expression of bcl-2 in PC12 cells does not mimic or interfere with $N G F$-induced neuronal differentiation}

PC1 2 cells cultured in serum-containing medium without NGF resemble immature precursors of noradrenergic adrenal chromaffin cells and sympathetic neurons, while NGF causes them to cease proliferation and acquire properties of sympathetic neurons, including neurite outgrowth (Greene and Tischler, 1976, 1982; Levi and Alemá, 1991). Although bcl-2, like NGF, promotes PC1 2 cell survival, it does not promote their neuronal differentiation. All clones that express either high or low levels of human bcl-2 protein lack neurites. Furthermore, no cells in our original, nonselected cultures transfected with SFFVBcl-2nl underwent spontaneous neurite outgrowth. We also asked whether high expression of bcl-2 in PC12 cells, besides pro- moting their survival in serum-free medium, might affect their ability to differentiate in the presence of NGF. To examine this issue we cultured various clones in complete medium with NGF for $7 \mathrm{~d}$ and measured the percentage of cells that responded to NGF by extending neurites. Data from representative clones are shown in Figure 6, $A$ and $B$. As shown, expression of bcl-2 does not compromise NGF-dependent neurite outgrowth. Comparable results were obtained with all bcl- 2 expressing clones (data not shown).

\section{Immunolocalization of human bcl-2 in transfected PCI2 cells}

A previous study has shown that bcl-2 is localized to mitochondrial membranes, thus providing a possible clue to its function (Hockenbery et al., 1990). In light of these data, we examined the localization of human bcl-2 protein in one of the highest-expressing $\mathrm{PC} 12$ clones, $\mathrm{PC} 12 \mathrm{bcl}-2.1$. Immunostaining of human bcl- 2 with the monoclonal antibody $6 \mathrm{C} 8$ and analysis with a laser-scanning confocal microscope shows a degree of punctate cytoplasmic staining similar to that obtained with streptavidin-Texas red, which targets mitochondria (Fig. 7). However, the fluorescein pattern is more diffuse than that seen with streptavidin-Texas red, suggesting that in these cells a substantial proportion of human bcl-2 protein is not localized to the mitochondria. Subcellular fractionation studies confirmed the mitochondrial localization of human bcl-2 in the transfected cells, but in addition revealed a significant proportion of human bcl-2 protein in the soluble fraction (data not shown).

\section{Discussion}

The proto-oncogene bcl-2 was discovered and characterized as a result of its involvement in the $t(14 ; 18)(\mathrm{q} 3221)$ chromosomal translocation that is the cytogenetic hallmark of human follicular B-cell lymphomas (Bakhshi et al., 1985; Cleary and Sklar, 1985; Tsujimoto et al., 1985). It was subsequently shown that bcl-2 is unique among proto-oncogenes in that it inhibits cell death rather than promoting cell division (Vaux et al., 1988; Hockenbery et al., 1990; Nuñez et al., 1990). Recent studies have established that bcl-2 can suppress programmed cell death (for review, see Korsmeyer 1992a,b). To this end, it has been shown that deregulated expression of bcl-2 prolongs survival of certain hematopoietic cell lines after growth factor deprivation and inhibits the accompanying internucleosomal DNA fragmentation. Moreover, bcl-2 expression in immature thymocytes of transgenic mice blocks glucocorticoid-, radiation-, and antiCD3-induced apoptosis (Sentman et al., 1991; Strasser et al., 1991). The actions of bcl-2 extend beyond the hematopoietic system. For instance, it has been reported recently that expression of human bcl-2 prolongs the survival of baculovirus-infected Sf9 insect cells (Alnemri et al., 1992). A broader site of action is also suggested by the physiological expression of bcl2 , which is not restricted to lymphoid tissues. Immunohistochemical studies in humans reveal that a limited number of mature tissues, all characterized by apoptotic cell death, express bcl-2 protein (Hockenbery et al., 1991). Interestingly, bcl-2 message is detected in newborn and adult brain and bcl-2 protein is found in some neurons in adult brain. The expression of bcl-2 in neurons, as well as in certain human neuroblastoma cell lines (Reed et al., 1991), is suggestive of a possible role in neuronal cell survival. Very recently, Garcia et al. (1992) demonstrated that overexpression of bcl-2 in cultured sympathetic neurons prevented their death after withdrawal of NGF. These workers suggested on this basis that bcl-2 might be involved in the mech- 


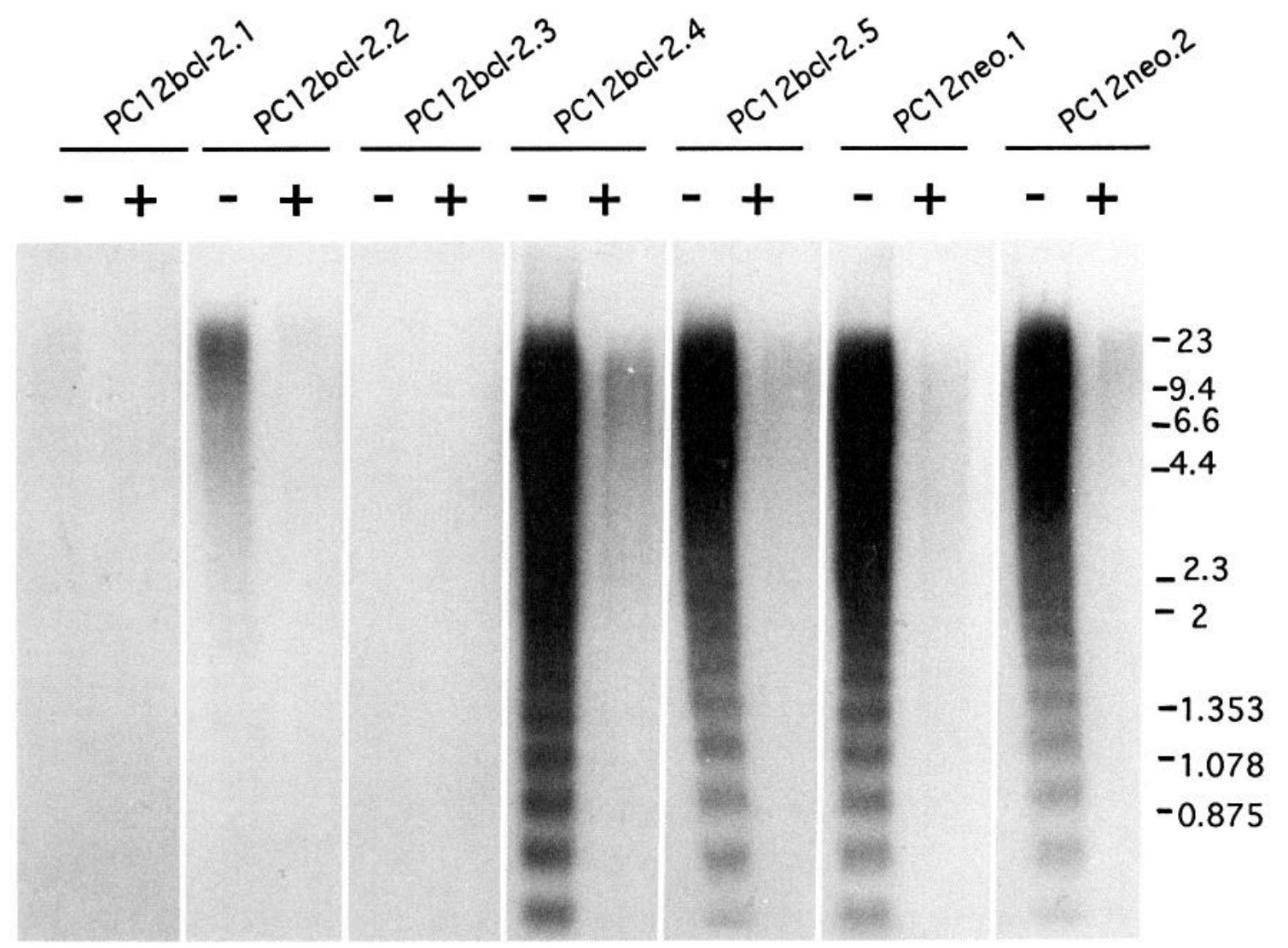

Figure 5. Expression of bcl-2 inhibits the early internucleosomal DNA fragmentation in serum-free medium. Cells from various clones were washed and cultured in serum-free RPMI 1640 medium, in the presence $(+)$ or absence $(-)$ of $100 \mathrm{ng} / \mathrm{ml} \mathrm{NGF}$ for $3 \mathrm{hr}$. Soluble DNA was extracted from the cultures and analyzed as described in Materials and Methods.

anism whereby NGF and other trophic factors prevent neuronal cell death.

The established role of bcl- 2 in inhibiting apoptotic cell death and its expression in the nervous system led us to introduce this gene by stable transfection into rat $\mathrm{PC} 12$ cells. Because $\mathrm{PC} 12$ cells are a model both for sympathetic nervous system development and for trophic factor-regulated neuronal cell death and survival, such cells may provide insight as to the mechanism and role of bcl-2 in the nervous system. We report here that expression of human bcl-2 protein inhibits the early internucleosomal DNA fragmentation and promotes the survival of PC12 cells deprived of trophic support. These effects are dependent on the amount of protein expressed, since clones that express relatively low levels of exogenous bcl-2 protein behave like controls. Although bcl-2 expression promoted PC12 cell survival, in no case did it provide long-term protection from death equivalent to that obtained with NGF. It is conceivable that higher levels of expression would have given longer survival. However, even with lymphocytes deprived of trophic factors, survival is prolonged by bcl- 2 vectors, but the cells are not indefinitely immortalized (Nuñez et al., 1990). Our PC12 cell studies also show that high expression of bcl-2 does not induce neuronal differentiation or interfere with the ability of NGF to promote neurite outgrowth.

Could bcl-2 mediate the actions of neurotrophic factors such as NGF? For PC12 cells and cultured sympathetic neurons, NGF is able to promote survival in the absence of protein or RNA synthesis (Martin et al., 1988; Rukenstein et al., 1990;
Edwards et al., 1991), and at least for PC12 cells, macromolecular synthesis is not required for suppression of early DNA fragmentation by NGF (Batistatou and Greene, 1993). Thus, present evidence indicates it unlikely that NGF acts by inducing expression of the bcl-2 gene. Consistent with this, Northern blot analysis of total $\mathrm{PC} 12$ cell RNA revealed that PC1 2 cells express relatively low levels of endogenous bcl- 2 message, even in the presence of NGF. These levels are much lower than the levels of exogenous human bcl-2 mRNA required to promote serumfree survival. Thus, the endogenous bcl- 2 levels in PC12 cells do not appear sufficient to promote their survival even after NGF treatment.

Although NGF does not appear to promote survival by inducing bcl-2, an alternative is that NGF may prevent death by activating preexisting bcl-2. Although there is no evidence that such a step is required for bcl-2 to maintain cell survival (e.g., human bcl-2 functions in PC12 cells in the absence of NGF or other exogenous trophic factors), it is conceivable that in overexpressing cells, enough bcl-2 protein becomes spontaneously activated to provide support in the absence of trophic factors.

Despite the uncertainty that bcl-2 mediates NGF-promoted survival, the present findings and the expression of this molecule in at least certain neurons raise possibilities for its role in the nervous system. For example, bcl-2 could be involved in supporting immature neurons or neuroblasts before they encounter and become dependent on trophic factors. Alternatively, or in addition, bcl- 2 could function in some mature neurons to assure survival of these long-lived cells. Such an activity could replace 


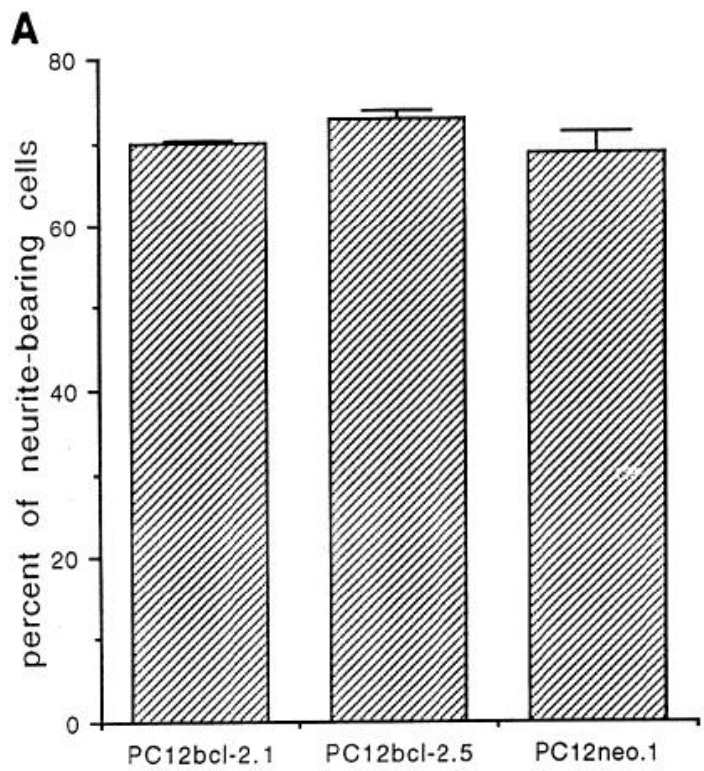

\section{B}
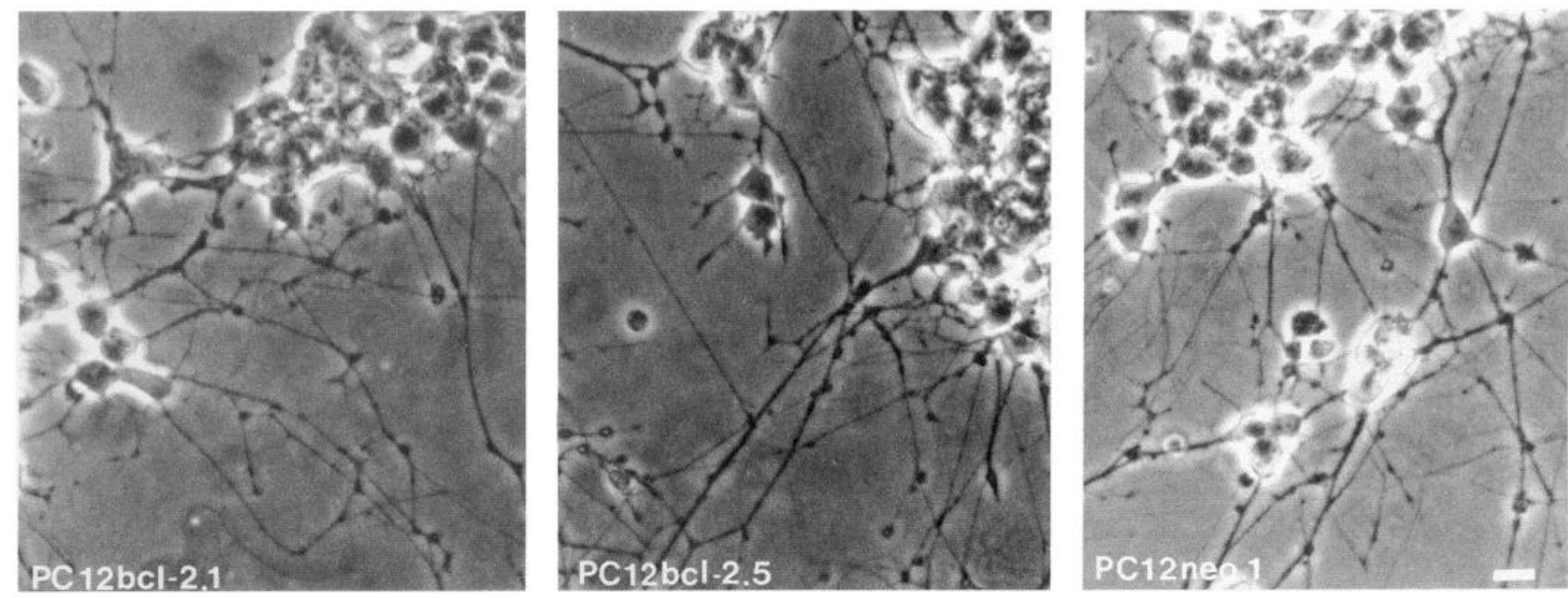

Figure 6. NGF-dependent neurite outgrowth from transfected clones. Cells from clones PC12bcl-2.1, PC12bcl-2.5, and PC12neo.1 were cultured in complete medium, in the presence $100 \mathrm{ng} / \mathrm{ml} \mathrm{NGF}$ for $7 \mathrm{~d}$. $A$, Cultures were scored for neurite bearing cells. Duplicate cultures were scored for each clone. Error bars represent SEM $(n=2)$. $B$, Phase-contrast micrographs of the same cultures. Scale bar, $10 \mu \mathrm{m}$.
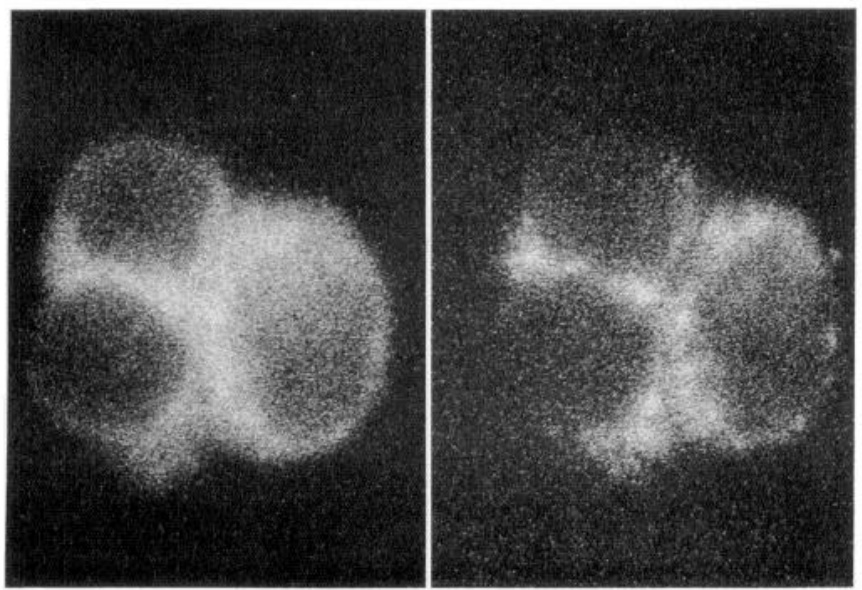

the need for extrinsically supplied trophic factors or could act as an alternative means to enhance the likelihood of survival if trophic support is lost or temporarily interrupted. This would be consistent with the suggestion that neurons may possess redundant survival mechanisms (Rukenstein et al., 1991).

The mechanism of action of bcl-2 remains elusive. Our study indicates that bcl-2 does not merely mimic NGF, since its expression does not lead to neuronal differentiation. Past studies have established that the survival and morphological differen-

Figure 7. Immunolocalization of human bcl-2 protein in transfected PC1 2 cells. Cells from clone PC12bcl-2.1 were grown on collagen-coated glass slides in complete medium. Immunostaining with monoclonal human bcl-2 antibody $6 \mathrm{C} 8$ (left) and incubation with streptavidinTexas red (right) were performed as described in Materials and Methods. 
tiation of $\mathrm{PC} 12$ cells and sympathetic neurons are promoted by scparatc pathways (Grecnc ct al., 1990; Batistatou and Greenc, 1991; Rukenstein et al. 1991). It appears that bcl-2, unlike NGF, affects only the survival-promoting pathway. Thus, it seems likely that NGF and bcl-2 utilize independent primary mechanisms. However, these may converge to promote neuronal cell survival by a common pathway. Investigation of the elements shared by cells responding to neurotrophic agents or expressing bcl-2 may therefore shed light on the mechanisms of neuronal cell survival and death. For these studies, as well as for biochemical and molecular biological studies addressing the mode of bcl-2 action, the utilization of neuronal cell lines that stably express bcl-2 will be particularly helpful. The bcl-2-expressing PC12 cell lines presented here provide the appropriate model systems for such investigations.

\section{References}

Alnemri ES, Robertson NM, Fernandes TF, Croce CM, Litwack G (1992) Overexpressed full-length human BCL2 extends the survival of baculovirus-infected Sf9 insect cells. Proc Natl Acad Sci USA 89: 7295-7299.

Bakhshi A, Jensen JP, Goldman P, Wright JJ, McBride OW, Epstein AL, Korsmeyer SJ (1985) Cloning the chromosomal breakpoint of $t(14 ; 18)$ human lymphomas: clustering around $J_{H}$ on chromosome 14 and near a transcriptional unit on 18. Cell 41:889-896.

Barde Y-A (1989) Trophic factors and neuronal survival. Neuron 2:1525-1534.

Batistatou A, Greene LA (1991) Aurintricarboxylic acid rescues PC12 cells and sympathetic neurons from cell death caused by nerve growth factor deprivation: correlation with suppression of endonuclease activity. J Cell Biol 115:461-471.

Batistatou A, Greene LA (1993) Internucleosomal DNA cleavage and neuronal cell survival/death. $J$ Cell Biol, in press.

Burstein DE, Greene LA (1978) Evidence for RNA synthesis-dependent and -independent pathways in stimulation of neurite outgrowth by nerve growth factor. Proc Natl Acad Sci USA 75:6059-6063.

Chomczynski P, Sacchi N (1987) Single step method of RNA isolation by acid guanidinium thiocyanate-phenol-chloroform extraction. Anal Biochem 162:156-159.

Cleary ML, Sklar J (1985) Nucleotide sequence of a $t(14 ; 18)$ chromosomal breakpoint in follicular lymphoma and demonstration of a breakpoint cluster region near a transcriptionally active locus on chromosome 18. Proc Natl Acad Sci USA 82:7439-7443.

Dipasquale B, Marini AM, Youle RJ (1991) Apoptosis and DNA degradation induced by 1-methyl-4-phenylpyridinium in neurons. Biochem Biophys Res Commun 181:1442-1448.

Edwards SN, Buckmaster AE, Tolkovsky AM (1991) The death program in cultured sympathetic neurons can be suppressed at the posttranslational level by nerve growth factor, cyclic AMP and depolarization. J Neurochem 57:2140-2143.

Garcia I, Martinou I, Tsujimoto Y, Martinou J-C (1992) Prevention of programmed cell death of sympathetic neurons by the bcl-2 protooncogene. Science 258:302-304.

Greene LA (1978) Nerve growth factor prevents the death and stimulates neuronal differentiation of clonal $\mathrm{PCl} 2$ pheochromocytoma cells in serum-free medium. J Cell Biol 78:747-755.

Greene L $\Lambda$, Tischler AS (1976) Establishment of a noradrenergic clonal line of rat adrenal pheochromocytoma cells which respond to nerve growth factor. Proc Natl Acad Sci USA 73:2424-2428.

Greene LA, Tischler AS (1982) PC12 pheochromocytoma cells in neurobiological research. Adv Cell Neurobiol 3:373-414.

Greene LA, Volonté C, Chalazonitis A (1990) Purine analogues inhibit nerve growth factor-promoted neurite outgrowth by sympathetic and sensory neurons. $J$ Neurosci 10:1479-1485.

Greene LA, Sobeih MM, Teng KK (1991) Methodologies for the culture and experimental use of the PC12 rat pheochromocytoma cell line. In: Culturing nerve cells (Banker G, Goslin K, eds), pp 207-226. Cambridge, MA, MIT Press.
Hamburger V, Oppenheim RW (1982) Naturally occurring neuronal death in vertebrates. Neurosci Comm 1:39-55.

Hockenbery DM, Nuñez G, Milliman C, Schreiber RD, Korsmeyer SJ (1990) $\mathrm{Bcl}-2$ is an inner mitochondrial membrane protein that blocks programmed cell death. Nature 348:334-336.

Hockenbery DM, Zutter M, Hickey W, Nahm M, Korsmeyer SJ (1991) Bcl-2 protein is topographically restricted in tissues characterized by apoptotic ccll dcath. Proc Natl Acad Sci USA 88:6961-6965.

Korsmeyer SJ (1992a) Bcl-2: a repressor of lymphocyte death. Immunol Today 13:285-288.

Korsmeyer SJ (1992b) Bcl-2 initiates a new category of oncogenes: regulators of cell death. Blood 80:879-886.

Kure S, Tominaga T, Yoshimoto T, Tada K, Narisawa K (1991) Glutamate triggers internucleosomal DNA cleavage in neuronal cells. Biochem Biophys Res Commun 179:39-45.

Levi A, Alemá S (1991) The mechanism of action of nerve growth factor. Annu Rev Pharmacol Toxicol 31:205-228.

Martin DP, Schmidt RE, DiStefano PS, Lowry OH, Carter JG, Johnson EM Jr (1988) Inhibitors of protein synthesis and RNA synthesis prevent neuronal death caused by nerve growth factor deprivation. $\mathbf{J}$ Cell Biol 106:829-844.

Negrini M, Silini E, Kozak C, Tsujimoto Y, Croce CM (1987) Molecular analysis of mbcl-2: structure and expression of the murine gene homologous to the human gene involved in follicular lymphoma. Cell 49:455-463.

Nuñez G, London L, Hockenbery D, Alexander M, McKearn JP, Korsmeyer SJ (1990) Deregulated Bcl-2 gene expression selectively prolongs survival of growth factor-deprived hematopoietic cell lines. J Immunol 144:3602-3610.

Oppenheim RW (1989) The neurotrophic theory and naturally occurring motoneuron death. Trends Neurosci 12:252-255.

Oppenheim RW (1991) Cell death during development of the nervous system. Annu Rev Neurosci 14:453-501.

Purves D (1986) The trophic theory of neural connections. Trends Neurosci 9:486-492.

Reed JC, Meister L, Tanaka S, Cuddy M, Yum S, Geyer D, Pleasure D (1991) Differential expression of bcl-2 protooncogene in neuroblastoma and other human tumor cell lines of neural origin. Cancer Res 51:6529-6538.

Rukenstein A, Rydel RE, Greene LA (1991) Multiple agents rescue PC1 2 cells from serum-free death by translation- and transcriptionindependent mechanisms. J Neurosci 11:2552-2563.

Rydel RE, Greene LA (1988) Cyclic AMP analogues promote survival and neurite outgrowth in cultures of rat sympathetic and sensory neurons independently of nerve growth factor. Proc Natl Acad Sci USA 85:1257-1261.

Sambrook J, Fritsch EF, Maniatis T (1989) Molecular cloning: a laboratory manual, 2d ed. Cold Spring Harbor, NY: Cold Spring Harbor Laboratory.

Sentman CL, Shutter JR, Hockenbery D, Kanagawa O, Korsmeyer SJ (1991) Bcl-2 inhibits multiple forms of apoptosis but not negative selection in thymocytes. Cell 67:879-888.

Server AC, Mobley WC (1991) Neuronal cell death and the role of apoptosis. In: Current communications in cell and molecular biology, Vol 3 (Tomei LD, Cope FO, eds), pp 263-278. Cold Spring Harbor, NY: Cold Spring Harbor Laboratory.

Soto AM, Sonnenschein C (1985) The role of estrogens on the proliferation of human breast tumor cells (MCF-7). J Steroid Biochem 23:87-94.

Strasser A, Harris AW, Cory S (1991) Bcl-2 transgene inhibits T-cell death and perturbs thymic self-censorship. Cell 67:889-899.

Tsujimoto Y, Gorham J, Cossman J, Jaffe E, Croce CM (1985) The $t(14 ; 18)$ chromosome translocations involved in B-cell neoplasms result from mistakes in VDJ joining. Science 229:1300-1303.

Vaux DL, Cory S, Adams JM (1988) Bcl-2 gene promotes hematopoietic cell survival and cooperates with c-myc to immortalize pre-B cells. Nature 335:440-442.

Wright LL, Cunningham TJ, Smolen AJ (1983) Developmental neuron death in the rat superior cervical sympathetic ganglion: cell counts and ultrastructure. J Neurocytol 12:727-738. 